\title{
eHealth Technologies Enable more Accessible Hearing Care
}

\author{
De Wet Swanepoel, Ph.D. ${ }^{1,2,3}$
}

\section{ABSTRACT}

Hearing loss is a pervasive global health care burden affecting up to one in every seven persons of whom $90 \%$ reside in low- and middleincome countries. Traditional service-delivery models are unable to support and promote accessible and affordable hearing care in these setting. Major barriers include a severe shortage of hearing health care professionals, costs associated with equipment, facilities and treatments, and centralized service-delivery models. Convergence of digital and connectivity revolutions are combining to enable new ways of delivering decentralized audiological services along the entire patient journey using integrated eHealth solutions. eHealth technologies are allowing nonprofessionals in communities (e.g., community health workers) to provide hearing services with point-of-care devices at reduced cost with remote surveillance and support by professionals. A growing body of recent evidence showcases community-based hearing care within an integrated eHealth framework that addresses some of the barriers of traditional service-delivery models at reduced cost. Future research, especially in lowand middle-income countries, must explore eHealth-supported hearing care services from detection through to treatment.

KEYWORDS: mHealth, telehealth, audiology

\section{HEARING LOSS IS A GLOBAL CHALLENGE}

The global prevalence of hearing loss affects a staggering 5 to $10 \%$ of the world's population, ${ }^{1,2}$ depending on the classification used. The global burden of disease study estimates that 1.3 billion people suffer from a hearing loss of $35 \mathrm{~dB}$ HL or greater. ${ }^{1}$ The World Health Organization (WHO) classifies disabling hearing loss as greater than $40 \mathrm{~dB} \mathrm{HL}$ for adults ( $30 \mathrm{~dB}$ for children) with a prevalence of 460 million, of which $90 \%$ reside in low- and middle-income countries (LMICs). ${ }^{1,2}$ Since age is the number one contributor to hearing
${ }^{1}$ Department of Speech-Language Pathology and Audiology, University of Pretoria, South Africa; ${ }^{2}$ Ear Sciences Centre, School of Surgery, University of Western Australia, Nedlands, Australia; ${ }^{3}$ Ear Science Institute Australia, Subiaco, Australia.

Address for correspondence: De Wet Swanepoel, Ph.D., Department of Speech-Language Pathology and Audiology, University of Pretoria, Pretoria 0002, South Africa (e-mail: dewet.swanepoel@up.ac.za).
Humanitarian Audiology; Guest Editor, Steven P. Smith, Au.D.

Semin Hear 2020;41:133-140. Copyright (C) 2020 by Thieme Medical Publishers, Inc., 333 Seventh Avenue, New York, NY 10001, USA. Tel: +1(212) 760-0888. DOI: https://doi.org/10.1055/s-0040-1708510. ISSN 0734-0451. 
loss and the world population is aging overall, the WHO estimates 900 million persons with disabling hearing loss by $2050 .^{2}$

Its invisible non-life-threatening nature has resulted in hearing loss being neglected as a global health priority. More recently, hearing loss has increasingly been recognized as an important global burden of disease. ${ }^{3}$ The global burden of disease study ranks age-related hearing loss as the fifth most significant contributor to disability after diabetes which is in fourth place. ${ }^{1}$ Untreated hearing loss also has a high associated economic burden with global hearing loss costs estimated at $\$ 750$ billion annually, which is equivalent to the gross domestic product of the Netherlands. $^{2}$

The impact of hearing loss on individuals affects not only social interaction and participation $^{4,5}$ but also general health and well-being. ${ }^{6}$ Persons with hearing loss are at higher risk of cognitive impairment, dementia, ${ }^{7}$ depression, lower household income and unemployment, and greater degrees of perceived social and emotional loneliness. ${ }^{8}$ In children, hearing loss can preclude or delay mastery of spoken language and, if not identified early, has a devastating impact on literacy, educational success, and socioemotional well-being. ${ }^{8}$

\section{Challenges to heARING CARE}

In light of the size, cost, and impact of the hearing loss epidemic, we find ourselves in an era where treatments for hearing loss have never been better and can dramatically alter outcomes. ${ }^{9,10}$ The principle treatments for hearing loss, depending on severity, are hearing aids and cochlear implants and have been demonstrated to be effective not only to improve communication but also on general health and well-being. ${ }^{8,9}$

Despite improving economies in LMICs to make interventions more feasible, uptake of care remains very limited. ${ }^{8}$ With only an estimated $3 \%$ of persons who can benefit from a hearing aid having access to one, the poor outcomes for affected persons are perpetuated. ${ }^{11}$ While there are multiple barriers that prohibit hearing services in LMICs, three of the most prominent include (1) limited availability of professional hearing care providers; (2) the costs associated with test equipment, facilities, and amplification options; and (3) centralized service-delivery models.

In a region like sub-Saharan Africa, where more than a billion persons reside, there is typically less than one hearing care professional to every million people and has shown no increase over the past 10 years. ${ }^{12,13}$ The cost associated with conventional audiological equipment for screening, diagnosis, intervention, and amplification is a major prohibitive factor. ${ }^{8,14}$ Typical audiological clinics employ expensive, stationary audiometric equipment with a sound booth or sound-treated environment that is often more expensive than the audiometer. In low-resource settings, the cost barrier is exacerbated by competing against infrastructure and operational budgets for acute and life-threatening conditions. As a result of the associated expense of typical audiological clinics, these services, if available at all, are usually centralized in metropolitan areas at specialized facilities. ${ }^{14}$ These factors further aggravate the entrenched barriers to access and affordability in hearing health service delivery.

Even with the goal to build human resource capacity, ${ }^{8}$ the disparity is so overwhelming that it becomes clear that radical rethinking of existing service-delivery models is necessary for any real impact to be realized in the near future. ${ }^{14}$

\section{EHEALTH TECHNOLOGIES ENABLE MORE ACCESS}

Convergence of the digital and connectivity revolutions is combining to enable new ways of delivering decentralized audiological services along the entire patient journey through integrated eHealth solutions. ${ }^{14-16}$ Personal digital technologies, smartphones, in particular, have seen an exponential growth in terms of processing power and capabilities alongside penetration rates that are reaching above $80 \%$ for adults in developed and developing countries. ${ }^{17}$ At the same time, with mobile networks now covering $99 \%$ of the global population, ${ }^{18}$ these technologies provide a powerful and ubiquitous tool for point-of-care health services, surveillance, and remote synchronous and asynchronous telehealth support. ${ }^{19}$ Capitalizing on these advances in technology and penetration of connectivity globally, in LMICs in particular, opens up innovative ways 
to deliver hearing services with the promise of improved access and affordability. ${ }^{19}$ In fact, improved mobile connectivity levels, in general, are associated with improved quality of life and progress toward meeting sustainable development goals. ${ }^{20}$

Digital technologies used in eHealth solutions can therefore minimize and even negate traditional barriers to hearing care that typically characterize LMICs while enabling new models of care for greater access and affordability. eHealth trends that can address existing challenges in hearing care access are considered in the following section (Table 1).

\section{Addressing Limited Access to Hearing Health Professionals}

Digital technologies are enabling a new cadre of providers who may be minimally trained per- sons (e.g., community health workers [CHWs] or lay health workers) but who can facilitate a range of services from screening through to diagnostics in partnership with professional healthcare providers. ${ }^{21,22}$ While task shifting in public health programs is a common strategy to increase access to services, incorporating eHealth allows for more advanced services and remote support to be provided. ${ }^{22}$

Point-of-care diagnostics for hearing loss using off-the-shelf smartphones and calibrated headphones linking to cloud-based data management allow for decentralized service provision by community-based persons like CHWs with remote support and surveillance by professionals. $^{22-25}$ This is made possible by simple, intuitive touchscreen user interfaces ${ }^{26}$ that incorporate automated testing, interpretation, and reporting while conducting rigorous real-time quality control. ${ }^{27}$ Automated audiometry allows

Table 1 Barriers to Traditional Hearing Care and Opportunities Using eHealth Technologies in Low- and Middle-Income Countries

\begin{tabular}{|c|c|}
\hline Traditional hearing care barriers & Enabling eHealth technologies \\
\hline $\begin{array}{l}\text { Limited access } \\
\text { to professionals }\end{array}$ & $\begin{array}{l}\text { Increase access } \\
\text { - Nonhearing professionals } \\
\text { - Automation } \\
\text { - Smart decision making (Al) } \\
\text { - Quality control } \\
\text { - Inclusive Uls }\end{array}$ \\
\hline $\begin{array}{l}\text { Costs (e.g., equipment, } \\
\text { environment, amplification, } \\
\text { support) }\end{array}$ & $\begin{array}{l}\text { Improve affordability } \\
\text { - Minimally trained persons } \\
\text { - Off-the-shelf technologies } \\
\text { - Environmental management and surveillance } \\
\text { - Amplification: } \\
\text { Diversification by established manufacturers and } \\
\text { competitive pricing by new players } \\
\text { Integrated with test equipment } \\
\text { Noncustom molds } \\
\text { Rechargeability } \\
\text { Remote support }\end{array}$ \\
\hline Centralized services & $\begin{array}{l}\text { Decentralized point-of-care } \\
\text { - Mobility } \\
\text { - Nonprofessional hearing care providers } \\
\text { - Community-based models, i.e., primary health care, } \\
\text { home-based, occupational, wellness, mobile } \\
\text { - Optimized triaging } \\
\text { - Point-of-care hearing aid fittings } \\
\text { - Remote support options }\end{array}$ \\
\hline
\end{tabular}

Abbreviations: Al, artificial intelligence; UI, user interfaces. 
for screening and diagnostics by using a simple patient response button on a smartphone for self-testing or operator-facilitated testing in young children. Using new methods of artificial intelligence could further optimize the testing to obtain more information in shorter periods. ${ }^{28}$

Using trained nonprofessionals like CHWs to provide services requires quality control metrics that advise on the feasibility of test environments and operator test reliability. ${ }^{21,29}$ Smartphone microphones allow accurate monitoring of environmental noise and can provide real-time feedback on compliance to maximum permissible ambient noise levels for operators and remote asynchronous interpretation of test reliability by professionals. ${ }^{24}$ The hearScreen app screening mode includes a randomized nonpresentation instance for pure tone audiometry screening, which means that at one of the presentations there will be no sound generated. The forcedchoice test response paradigm requires operators to indicate if the person or child responded. If operators indicate that there was a response present, this gets logged against their profile providing a quality index score for every operator. ${ }^{29}$ Other quality indices collected for self-test audiometry include average response times, falsepositive responses, and retesting at $1 \mathrm{kHz}$ to provide a holistic impression of test quality. Cloud-based data management systems further allow audiology professionals to monitor the quality index of operators, like CHWs, to initiate retraining when necessary and to evaluate the quality of individual test results. ${ }^{29}$

\section{Addressing Costs (Equipment, Facilities, and Treatment)}

eHealth services utilizing off-the-shelf digital technologies, such as smartphones, are enabling for point-of-care diagnostics at dramatically reduced costs. A recent study illustrates this trend very poignantly with the use of consumer smartphones to assess middle ear functioning using acoustic reflectance, demonstrating results equivalent to commercial devices. ${ }^{30}$ Similarly, smartphones connected to calibrated transducers, which adhere to international medical device standards, allow clinical audiometry at significantly reduced costs. ${ }^{21,24}$ Apart from hearing assessment technologies, facilities typically used for clinical audiometry have traditionally required expensive and stationary sound booths. ${ }^{14}$ Digital technologies with insert earphones covered by circumaural earcups offer attenuation levels equivalent to a single-walled sound booth. ${ }^{31}$ Incorporating real-time environmental noise monitoring alongside these advanced attenuation options is allowing clinical audiometry to be moved outside of traditional sound booths with major cost-saving implications. ${ }^{14}$

A persistent challenge to treatment of hearing loss, not only in LMICs, is the prohibitive costs associated with hearing aids. ${ }^{8}$ Dramatic cost reductions may, however, be realized with recent trends including the use of personal amplification devices, over-the-counter hearing aids, large-scale hearing aid purchasing, and even the use of smartphone apps as amplification options. ${ }^{8}$ There has also been rapid growth and diversification in new hearing aid and consumer electronics manufacturers that are making treatment options more varied and affordable. Convergence of technological advancements in hearing aids and consumer amplification options (e.g., hearables) will increasingly level the playing field between manufacturers and should translate into more competitive pricing. Furthermore, the rapid shift to rechargeable hearing aids is beginning to address the continual cost barrier of batteries which has often rendered hearing aid use in LMICs unsustainable in the past.

\section{Addressing Centralized Service Delivery}

The mobility and affordability of digital eHealth hearing care technologies used by nonhearing health professionals are powerful enablers for decentralized access through community-based service delivery. ${ }^{21,32,33}$ Recent studies have demonstrated the feasibility of communitybased hearing screening for children and adults facilitated by community or lay health workers in schools, preschools, and homes using eHealth technologies with remote audiological support. ${ }^{21,25,29,34}$ Integrated cloud data management systems allow these eHealth technologies to send text message referrals based on geolocation. Diagnostic services at primary health care clinics, using the same platform, allows viewing of patient test results, tracking follow-up returns, 
and facilitating automated diagnostic audiometry and remote review by an audiologist to support treatment or referral decisions. ${ }^{32}$ While there is still a lack of evidence with regard to costs and cost-effectiveness in decentralized community-based hearing care, ${ }^{32}$ initial results from studies and evidence from other fields are demonstrating lower costs. ${ }^{21,32}$

Treatment options in the form of hearing aids have traditionally been one of the leading bottlenecks for decentralized service delivery in hearing. Larger fitting ranges with noncustom earmold hearing aids (e.g., receiver-in-canal and instant fit tips/domes) and self- or assisted-fitting options with remote support are opening up new opportunities for community-based interventions for straightforward cases. This leaves more complex cases, typically constituting less than $15 \%$ of hearing losses, ${ }^{8}$ to be referred for advanced assessment and treatment which may be more difficult to access in LMICs. While patients may still need some face-to-face support, especially with app-based services, trained non-health professionals could be employed. ${ }^{35}$ Furthermore, hearing aid connected apps that enable remote communication between patients and providers can be a viable method to support hearing aid users with trouble shooting and fine tuning. ${ }^{36}$ Adult aural rehabilitation is another area where eHealth technologies are demonstrating the potential to decentralize services at lower costs through remote support while improving self-management of hearing loss. ${ }^{37}$

\section{EXAMPLE OF EHEALTH-ENABLED COMMUNITY-BASED HEARING CARE}

In recent years, we have endeavored to develop, implement, and evaluate several communitydelivered hearing care models using eHealth technologies facilitated by minimally trained persons in a variety of low-income settings. ${ }^{21,25,29,34}$ Using task shifting, ${ }^{32}$ minimally trained persons in these implementation studies have included lay community members, $\mathrm{CHWs}$, community care workers, and teachers. Hearing services have included awareness initiatives, hearing screening, referral, follow-up, and diagnostics within home, preschool, school, and clinic settings. ${ }^{21,25,29,34}$ Community members providing these services are consistently positive in terms of ease of use, need for services, value to the community, and time efficiency. ${ }^{25,34}$

A recent implementation study investigated mHealth-supported community-based preschool screening in low-income communities in the Western Cape, South Africa. With no systematic screening programs in LMICs,
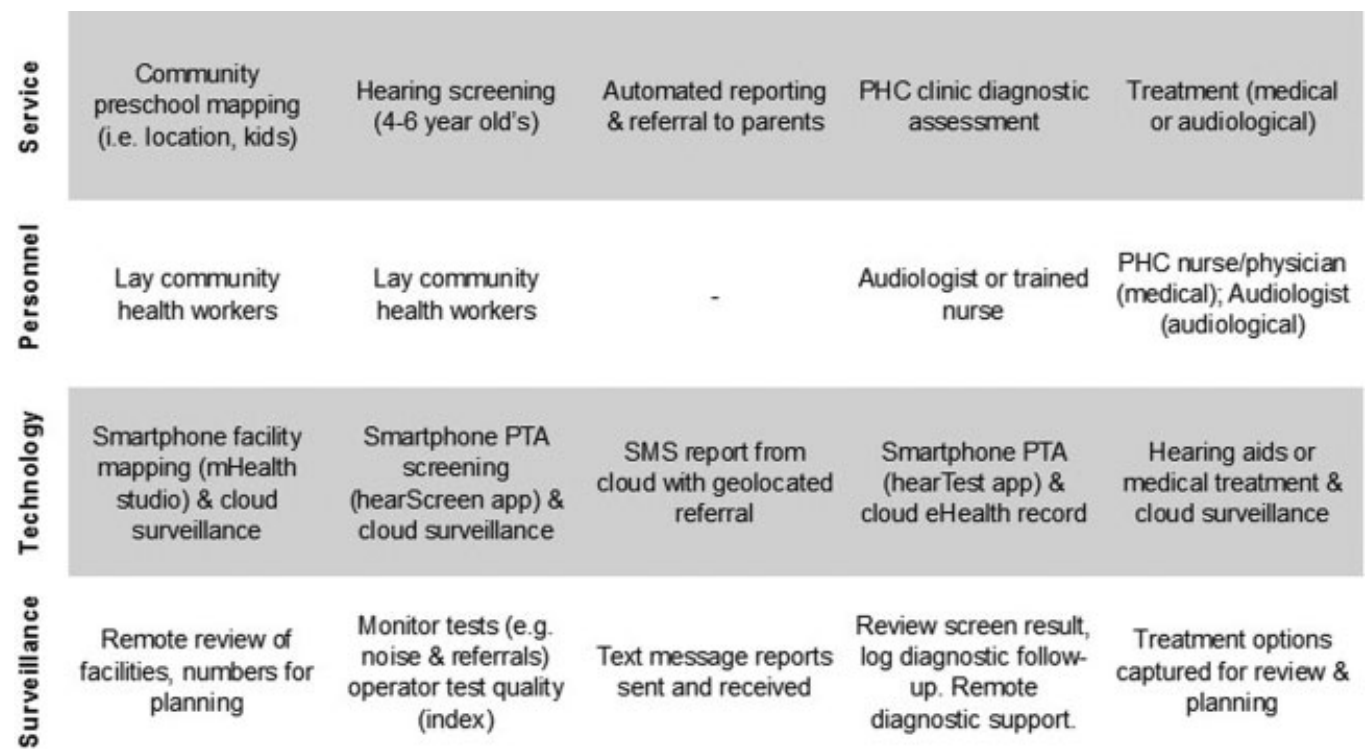

Figure 1 Community-based preschool hearing screening facilitated by trained lay health workers using eHealth technologies. 
hearing losses typically go undetected until school age where they have a devastating impact on development and outcomes, including academic and socioemotional well-being. This project was unique in that it drafted unemployed community members and trained them as lay CHWs providing both hearing and vision screening at preschool centers. These CHWs use mHealth point-of-care apps (hearScreen, hearX group and Peek Acuity, Peek Vision) to conduct systematic screenings within an integrated mHealth platform (mHealth studio, hearX group) that manages patient, facility, and test data for reporting and remote surveillance (Fig. 1).

This eHealth-supported community program with four trained lay $\mathrm{CHW}$ screeners (Fig. 2) demonstrated, over 16 months, how more than 8,000 young children (4-7 years of age) were screened for hearing and vision loss across 271 community preschool centers, yielding 111 children with hearing and/or visual impairment. ${ }^{21}$ Hearing and vision screening referral rates (5.2 and 2.1\%, respectively) and primary health care follow-up return rates (76 and $64 \%$, respectively) were within acceptable ranges, for hearing in particular. Point-of-care mHealth technologies allowed monitoring of test quality and environmental compliance and demonstrated that noise levels at $1 \mathrm{kHz}$ significantly influenced hearing screening outcomes. For example, remote surveillance by audiologists allowed for protocol adjustments to raise screening levels at $1 \mathrm{kHz}$ by $5 \mathrm{~dB}$. While there has been limited evidence showing reduced costs with community-delivered hearing care, ${ }^{32}$ this study demonstrated cost-effectiveness with a per-child cost of $\$ 5.63$ for the inclusive hearing and vision service. $^{21}$

\section{CONCLUSION}

The enormous disparity between the global need for hearing health care and the inability of traditional models of service delivery by trained professionals to address this need is a clear call for new ways of making hearing care widely accessible. eHealth technologies, while not an answer in and of itself, provide powerful tools that enable decentralized, communitydelivered models of care with remote audiology surveillance and support. A growing body of

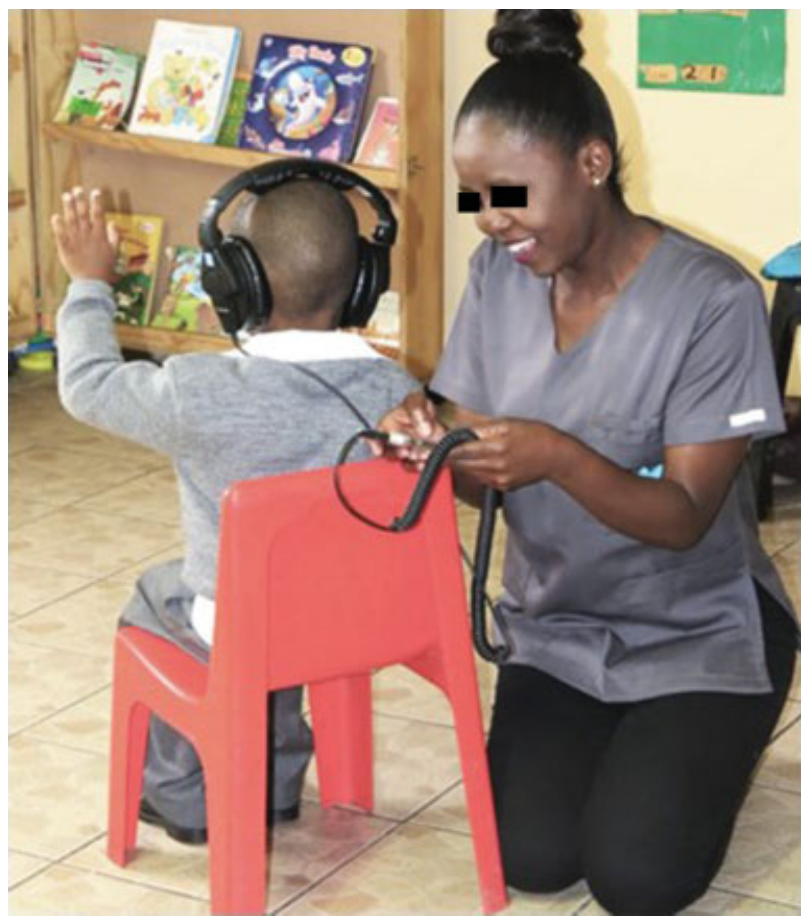

Figure 2 Community lay health worker screening preschool child in early childhood development center. 
recent evidence is showcasing communitybased hearing care within an integrated eHealth framework that can address some of the main barriers in traditional models of hearing care. Future research, especially in LMICs, needs to investigate eHealth-supported hearing care services from detection through to intervention and ongoing support.

\section{CONFLICT OF INTEREST}

The author is a cofounder and scientific advisor to the hearX group. His relationship includes equity and consulting.

\section{REFERENCES}

1. GBD 2017 Disease and Injury Incidence and Prevalence Collaborators. Global, regional, and national incidence, prevalence, and years lived with disability for 354 diseases and injuries for 195 countries and territories, 1990-2017: a systematic analysis for the Global Burden of Disease Study 2017. Lancet 2018;392(10159):1789-1858

2. World Health Organisation. WHO global estimates on prevalence of hearing loss. 2018. Available at: https://www.who.int/deafness/estimates/en/. Accessed September 6, 2019

3. Olusanya BO, Neumann KJ, Saunders JE. The global burden of disabling hearing impairment: a call to action. Bull World Health Organ 2014;92 (05):367-373

4. Gopinath B, Schneider J, McMahon CM, Teber E, Leeder SR, Mitchell P. Severity of age-related hearing loss is associated with impaired activities of daily living. Age Ageing 2012;41(02):195-200

5. Weinstein BE, Sirow LW, Moser S. Relating hearing aid use to social and emotional loneliness in older adults. Am J Audiol 2016;25(01):54-61

6. Gopinath B, Schneider J, Hickson L, et al. Hearing handicap, rather than measured hearing impairment, predicts poorer quality of life over 10 years in older adults. Maturitas 2012;72(02):146-151

7. Lin FR, Yaffe K, Xia J, et al; Health ABC Study Group. Hearing loss and cognitive decline in older adults. JAMA Intern Med 2013;173(04):293-299

8. Wilson BS, Tucci DL, Merson MH, O'Donoghue GM. Global hearing health care: new findings and perspectives. Lancet 2017;390(10111):2503-2515

9. Ferguson MA, Kitterick PT, Chong LY, Edmondson-Jones M, Barker F, Hoare DJ. Hearing aids for mild to moderate hearing loss in adults. Cochrane Database Syst Rev 2017;9:CD012023

10. Yoshinaga-Itano C. Universal newborn hearing screening programs and developmental outcomes. Audiol Med 2009;3:199-206
11. World Health Organization. Millions of people in the world have hearing loss that can be treated or prevented. 2013. Available at: https:/www.who.int/ $\mathrm{pbd} /$ deafness/news/Millionslivewithhearingloss.pdf. Accessed September 6, 2019

12. Mulwafu W, Ensink R, Kuper H, Fagan J. Survey of ENT services in sub-Saharan Africa: little progress between 2009 and 2015. Glob Health Action 2017;10(01):1289736

13. World Health Organization. Multi-country Assessment of National Capacity to Provide Hearing Care. Geneva: Switzerland. 2013. Available at: https://www.who.int/pbd/publications/WHOReportHearingCare_Englishweb.pdf?ua=1. Accessed September 6, 2019

14. Swanepoel DW, Olusanya BO, Mars M. Hearing healthcare delivery in sub-Saharan Africa-a role for tele-audiology. J Telemed Telecare 2010;(16): 53-56

15. Swanepoel D, Clark JL. Hearing healthcare in remote or resource-constrained environments. J Laryngol Otol 2019;133(01):11-17

16. Swanepoel W, Hall JW III. A systematic review of telehealth applications in audiology. Telemed J E Health 2010;16(02):181-200

17. Wigginton C, Curran M, Brodeur C. Global mobile consumer trends: Second edition. 2017. Available at: https://www2.deloitte.com/global/ en/pages/technology-media-and-telecommunications/articles/gx-global-mobile-consumer-trends. html. Accessed September 6, 2019

18. The World Bank. Mobile network coverage, $\%$ pop. 2016. Available at: https://tcdata360.worldbank.org/ indicators/entrp.mob.cov?country=BRA\&indicator =3403\&viz=line_chart\&years=2012,2016\&indicators =944\&compareBy=region. Accessed September 6, 2019

19. Swanepoel D, Smits C, De Sousa KC, Moore D. Mobile apps to screen for hearing loss: Opportunities and challenges. Bull World Health Organ 2019;97(10):717-718

20. Global System Mobile Association. The Mobile Economy. 2019. Available at: https://www. gsmaintelligence.com/research/?file=b9a6e6202ee1d5f787cfebb95d3639c5\&download. Accessed September 6, 2019

21. Eksteen S, Launer S, Kuper H, Eikelboom RH, Bastawrous A, Swanepoel D. Implementation of hearing and vision services for preschool children in low-income communities. Bull World Health Organ 2019;97(10):672-680

22. Suen JJ, Bhatnagar K, Emmett SD, et al. Improving access to hearing care across the life course through community-delivered care. Bull World Health Organ 2019;97(10):681-690

23. Sandström J, Swanepoel W, Carel Myburgh H, Laurent C. Smartphone threshold audiometry in underserved primary health-care contexts. Int J Audiol 2016;55(04):232-238 
24. Swanepoel W, Myburgh HC, Howe DMMahomed F, Eikelboom RH. Smartphone hearing screening with integrated quality control and data management. Int J Audiol 2014;53(12): 841-849

25. Yousuf Hussein S, Wet Swanepoel D, Biagio de Jager L, Myburgh HC, Eikelboom RH, Hugo J. Smartphone hearing screening in mHealth assisted community-based primary care. J Telemed Telecare 2016;22(07):405-412

26. Castillo NM, Vosloo S. HearScreen: case study by UNESCO-Pearson Initiative for Literacy. 2017. Available at: http://unesdoc.unesco.org/images/ 0025/002588/258877E.pdf. Accessed May 22, 2019

27. Clark JL, Swanepoel W. Technology for hearing loss-as we know it, and as we dream it. Disabil Rehabil Assist Technol 2014;9(05):408-413

28. Barbour DL, Howard RT, Song XD, et al. Online machine learning audiometry. Ear Hear 2019;40 (04):918-926

29. Yousuf Hussein S, Swanepoel W, Mahomed F, Biagio de Jager L. Community-based hearing screening for young children using an mHealth service-delivery model. Glob Health Action 2018; 11(01):1467077

30. Chan J, Raju S, Nandakumar R, Bly R, Gollakota S. Detecting middle ear fluid using smartphones. Sci Transl Med 2019;11(492):eaav1102

31. Swanepoel W, Matthysen C, Eikelboom RH, Clark JL, Hall JW III. Pure-tone audiometry outside a sound booth using earphone attenuation, integrated noise monitoring, and automation. Int J Audiol 2015;54(11):777-785

32. Suen JJ, Bhatnagar K, Emmett SD, et al. Hearing care across the life course provided in the community. Bull World Health Organ 2019;97(10):681-690

33. Suen JJ, Marrone N, Han HR, Lin FR, Nieman $\mathrm{CL}$. Translating public health practices: community-based approaches for addressing hearing health care disparities. Semin Hear 2019;40(01):37-48

34. van Wyk T, Mahomed-Asmail F, Swanepoel W. Supporting hearing health in vulnerable populations through community care workers using mHealth technologies. Int J Audiol 2019;58(11):790-797

35. Convery E, Keidser G, Hickson L, Meyer C. Factors associated with successful setup of a selffitting hearing aid and the need for personalized support. Ear Hear 2019;40(04):794-804

36. Convery E, Keidser G, McLelland M, Groth J. A smartphone app to facilitate remote patient-provider communication in hearing health care: Usability and effect on hearing aid outcomes. Telemed J E Health 2019. Doi: 10.1089/tmj.2019.0109. Available at: https://pubmed.ncbi.nlm.nih.gov/31433259a-smartphone-app-to-facilitate-remote-patient-provider-communication-in-hearing-health-care-usability-and-effect-on-hearing-aid-outcomes/. Accessed March 5, 2020

37. Ferguson M, Maidment D, Henshaw H, Heffernan E. Evidence-based interventions for adult aural rehabilitation: That was then, this is now. Semin Hear 2019;40(01):68-84 